\title{
BMJ Open Outcomes of a specialist weight management programme in the UK National Health Service: prospective study of 1838 patients
}

\author{
Jennifer Logue, ${ }^{1}$ Gwen Allardice, ${ }^{2,3}$ Michelle Gillies, ${ }^{4}$ Lorna Forde, ${ }^{3}$ \\ David S Morrison ${ }^{2,4}$
}

To cite: Logue J, Allardice G, Gillies M, et al. Outcomes of a specialist weight management programme in the UK National Health Service: prospective study of 1838 patients. BMJ Open 2014:4:e003747. doi:10.1136/bmjopen-2013003747

- Prepublication history and additional material for this paper is available online. To view these files please visit the journal online (http://dx.doi.org/10.1136/ bmjopen-2013-003747).

Received 7 August 2013 Revised 19 November 2013 Accepted 20 November 2013

\section{CrossMark}

${ }^{1}$ Institute of Cardiovascular and Medical Sciences, University of Glasgow, Glasgow, UK

${ }^{2}$ West of Scotland Cancer Surveillance Unit, UK ${ }^{3}$ NHS Greater Glasgow and Clyde, Glasgow, UK ${ }^{4}$ Institute of Health and Wellbeing, University of Glasgow, Glasgow, UK

Correspondence to Dr David S Morrison; david.morrison@glasgow.ac.uk

\section{ABSTRACT}

Objectives: There is limited evidence on the effectiveness of weight management programmes provided within routine healthcare and inconsistent use of outcome measures. Our aim was to evaluate a large National Health Service (NHS) weight management service and report absolute and proportional weight losses over 12 months.

Design: Prospective observational study.

Setting: Glasgow and Clyde Weight Management Service (GCWMS), which provides care for residents of NHS Greater Glasgow and Clyde area (population 1.2 million).

Participants: All patients who began GCWMS between 1 October 2008 and 30 September 2009.

Interventions: Structured educational lifestyle programme employing cognitive behavioural therapy, $600 \mathrm{kcal}$ deficit diet, physical activity advice, lower calorie diet and pharmacotherapy.

Primary and secondary outcomes measures: Baseline observation carried forward (BOCF), last observation carried forward (LOCF) and changes in programme completers reported using outcomes of absolute $5 \mathrm{~kg}$ and $5 \%$ weight losses and mean weight changes at a variety of time points.

Results: 6505 referrals were made to GCWMS, 5637 were eligible, 3460 opted in and 1916 (34\%) attended a first session. 78 patients were excluded from our analysis on 1838 patients. $72.9 \%$ of patients were women, mean age of all patients at baseline was 49.1 years, $43.3 \%$ lived in highly socioeconomically deprived areas and mean weights and body mass indices at baseline were $118.1 \mathrm{~kg}$ and $43.3 \mathrm{~kg} / \mathrm{m}^{2}$, respectively. $26 \%$ lost $\geq 5 \mathrm{~kg}$ by the end of phase 1 , $30 \%$ by the end of phase 2 and $28 \%$ by the end of phase 3 (all LOCF). Weight loss was more successful among men, particularly those $\leq 29$ years old.

Conclusions: Routine NHS weight management services may achieve moderate weight losses through a comprehensive evidence-based dietary, activity and behavioural approach including psychological care. Weight losses should be reported using a range of outcome measures so that the effectiveness of different services can be compared.
Strengths and limitations of this study

- Describes a large National Health Service (NHS) programme for severe and complex obesity.

- Comprehensive reporting of outcomes using a variety of measures to allow comparison with other studies.

- Lack of some baseline clinical risk factor data.

- Course completion defined using a lower threshold than some other studies.

\section{INTRODUCTION}

The prevalence of obesity, defined as a body mass index (BMI) of $30 \mathrm{~kg} / \mathrm{m}^{2}$ or greater, has increased steeply over the past three decades to become a major public health concern. ${ }^{1-3}$ Obesity raises the risk of many serious diseases, including coronary artery disease and cancers. ${ }^{4}$ In the UK, national guidelines recommend multicomponent weight management programmes involving calorie deficient diets, physical activity and behavioural components for the management of patients who are either overweight or obese. ${ }^{5} 6$ Despite these recommendations, the provision of weight management services across the UK remains patchy and there is limited published evidence of the effectiveness of such interventions outside of a research setting within the National Health Service (NHS)..$^{7-10}$

There is a variety of different methods used when reporting weight management outcomes, with no agreed standard methodology for analysis or follow-up period, which makes comparison between programmes complicated. It is, therefore, difficult for health authorities to make an informed choice when commissioning weight management services. Some studies include self-reported weights ${ }^{11}$ even though these are likely to be significantly underestimated. ${ }^{12}$ Weight loss programmes 
have variable lengths so that reported weight loss outcomes may represent changes over a few weeks or over a year. It is difficult to infer if weight losses reported at 12 weeks will be sustained in the medium to long term. ${ }^{7-9}$ Attendance is often poor but there is no consensus on whether outcomes should be reported only on programme completers, on all those who start a programme or carried-forward from the last observation. Programme completion has variously been defined as attendance at greater than $80 \%, 83 \%$ or $50 \%$ of sessions and it might be argued that because of the association between attendance and successful weight loss, higher thresholds will selectively identify patients with greater weight losses. ${ }^{79} 13$ There is also lack of agreement on which outcomes to publish with some studies reporting mean weight changes, proportional weight loss or absolute weight loss.

Only a small number of UK-based weight management programmes have published 12-month outcome data and the majority of these have been within a study setting. ${ }^{10} 111314$ The Counterweight Programme is delivered in primary care with training of primary care staff provided by a specialist team (mean baseline BMI $37 \mathrm{~kg} / \mathrm{m}^{2}$ ). ${ }^{13}$ The Counterweight Programme report that $31 \%$ of patients achieved $\geq 5 \%$ weight loss in those completing the programme though this attenuates to just $13.9 \%$ when all patients are included; however, as this was an audit rather than a study, there were no resources available to obtain measured or self-reported weights in those who dropped out. ${ }^{13}$ The other published research is based on commercial programmes with Jebb et $\mathrm{al}^{14}$ reporting 12-month weight loss outcomes from a randomised trial of WeightWatchers group sessions compared with general practitioner (GP) care alone (mean baseline BMI $31 \mathrm{~kg} / \mathrm{m}^{2}$ ), though this study included patients outside the UK. A recent trial of primarycare based interventions concluded that those provided by the NHS were ineffective. ${ }^{11}$ The Lighten Up Study ${ }^{11}$ compared random allocation to a number of weight management providers including commercial, pharmacy and primary care services; where direct measurement was unavailable due to non-attendance, final weight was sought by self-report. The mean BMI in Lighten Up was $33.8 \mathrm{~kg} /$ $\mathrm{m}^{2}$. Weight Watchers had $46 \%$ of patients achieving $\geq 5 \%$ weight loss in Jebb et $a l^{14}$ and $31 \%$ in Jolly et $a l^{11}$ (the most successful of all the programmes offered in that study) using measured plus self-reported 12-month weights.

There is currently no UK-based programme reporting 1 year outcomes for those patients with higher BMIs and complex comorbidities. Our aim was, therefore, to report 1 year outcomes from the NHS Greater Glasgow and Clyde Weight Management Service (GCWMS), an integrated service across primary and secondary care for patients with severe obesity and obesity-related comorbidities, including a large number of patients from areas of high socioeconomic deprivation. We previously presented the results of the first phase of this programme. ${ }^{15}$ We have reported percentage and absolute weight losses using both last and baseline observations to allow maximum comparison with other services.
METHODS

\section{Setting}

In NHS Greater Glasgow and Clyde (NHSGGC) area, population 1.2 million, a multicomponent weight management programme, the GCWMS, is available to patients aged 18 years and over with complex obesity (defined as BMI of $\geq 30 \mathrm{~kg} / \mathrm{m}^{2}$ with obesity-related comorbidities or BMI of $\geq 35 \mathrm{~kg} / \mathrm{m}^{2}$ ) referred by their GP or hospital doctor. The service, which is integrated across primary and secondary care but delivered in community-based sites, aims to achieve a $\geq 5 \mathrm{~kg}$ weight loss. In the hierarchy of interventions for the treatment of obesity in NHSGGC this service sits above local authority, commercial and thirdsector services, on the pathway to bariatric surgery. The GCWMS model was developed in 2004 and extended throughout the Health Board area in 2008.

The intervention is a time-limited structured educational lifestyle programme employing cognitive behavioural therapy techniques alongside a $600 \mathrm{kcal}$ deficit diet and physical activity advice. Phase 1 of the intervention includes nine 90 min sessions delivered fortnightly over a 16-week period. On finishing phase 1 patients can choose to enter phase 2, which consists of three 1-h sessions delivered at monthly intervals and includes a range of treatment options including further lifestyle advice, prescribed low-calorie diet or pharmacotherapy (orlistat). At the end of phase 2, or directly from the end of phase 1, dependent on patient choice, patients enter a weight maintenance programme (phase 3) comprising $121 \mathrm{~h}$ sessions delivered at monthly intervals. Patients who fail to achieve their target weight loss can choose to repeat phase 2 once more and then enter the maintenance programme or if they fail to lose $5 \mathrm{~kg}$ and have a BMI $>40 \mathrm{~kg} / \mathrm{m}^{2}$, or $\mathrm{BMI}>35 \mathrm{~kg} / \mathrm{m}^{2}$ with comorbidities, can opt for bariatric surgery.

\section{Definitions of completers and time points}

Patients were considered to be 'completers' if they attended about half of the sessions in any phase. Thus, in phase 1, completers had attended four or more appointments; in phase 2, they had attended two or more appointments; and in phase 3, they had attended six or more appointments. For the time-specific outcomes, there was often not a clinic date on the exact date or week corresponding to 3,6 or 12 months so we defined these periods as follows. For 3 months, we sought a weight at 84 days (12 weeks). If no weight was available at that time point, we used a later weight up to 98 days after starting the programme, or if that was also unavailable, a weight from 70 days onwards was used. For 6 months, we sought a weight at 182 days (26 weeks). If no weight was available, we used a later weight up to 210 days, or, if unavailable, a weight on or after 154 days was used. For 12 months, we sought a weight at 364 days, and if none was available, we extended the range up to 422 days, and if no weight was available, we extended it down to 308 or more days. 
The service is funded entirely by the NHSGGC Health Board. In 2009, the service employed 37.5 whole time equivalent staff including 1 service lead, 5 team leaders, 11.5 dieticians, 5.5 clinical psychologists, 1 psychology assistant, 4.2 physiotherapists, 6.3 administrative staff and 3 technical support staff. In the year 2008/2009, staff costs were estimated to be $£ 1.25$ million. Additional resources required to deliver the intervention include scales, magnetic flip charts, laptops and projectors and appropriately adapted seating, provided at an estimated non-recurring set-up cost of $£ 20000$. There are no direct costs to patients entering the GCWMS; however, patients are required to cover any transportation costs to and from appointments.

\section{Data and statistical methods}

All referrals to the GCWMS from 1 October 2008 to 30 September 2009 were followed until they completed or left the programme. Data were censored at 1 December 2011, so that full data were available on patients who completed phase 3, which occurred around 19 months after starting the programme. Weight change from entry to the programme to the end of phases 1-3 is described. For comparison with other published studies, weight change from entry to the programme to 3,6 and 12 months is also described. Primary analyses were carried out in all patients who began treatment. Missing data occur when patients fail to attend appointments or leave the programme early; reasons for non-attendance are generally not known. Where data were missing, the method of last observation carried forward (LOCF) was preferred though baseline observation carried forward (BOCF) is also reported. All analyses were performed using the STATA Statistical Software Package V.11.

\section{Socioeconomic status}

As individual, social, educational and economic information were not available for patients, we used the Scottish Index of Multiple Deprivation (SIMD) ${ }^{16}$ to infer socioeconomic status. This is a validated area-based measure of socioeconomic circumstances that uses individuals' postcode of residence. The SIMD does not measure individuals' socioeconomic status but that of their area of residence. The SIMD ranks 6505 small geographical areas (datazones) across Scotland, each containing approximately 750 people from most deprived (1) to least deprived (6505). These have been further categorised into quintiles where 1 is most deprived and 5 is least deprived. The SIMD score is composed of information on seven domains: (1) income and benefits, (2) employment in working age population, (3) health and healthcare utilisation, (4) educational attainment, skills and training, (5) access to services and transport, (6) recorded crime rates and (7) housing quality and overcrowding.

\section{Ethics approval}

Non-identifiable data were provided by GCWMS for the purposes of evaluating a routine NHS service. The work was, therefore, not considered to require ethics committee approval.

\section{RESULTS}

Over the 1-year period from October 2008 to September 2009, 6505 referrals were made to GCWMS, of whom 5637 were eligible for the service, based on BMI, age, area of residence and comorbidities. Of the 5637 eligible patients, $61 \%$ (3460) opted into the service, $58 \%$ (3249) attended for assessment, 3 were deemed ineligible at assessment because their BMI was lower than $30 \mathrm{~kg} / \mathrm{m}^{2}, 38 \%$ (2153) opted to enter phase 1 and $34 \%$ (1916) attended phase 1 at least once. From the dataset of 1916 patients, we excluded a further 4 whose initial BMI was recorded as $\leq 30 \mathrm{~kg} / \mathrm{m}^{2}$ and 74 who were directed to a specialised disordered eating group (where they received different, specialised psychological interventions that are qualitatively different from the main programme), leaving a final sample for analysis of 1838 patients. The majority of the 1838 patients were woman $(72.9 \%)$, the mean age was 49.1 years (SD 13.5) and men were older than women (mean ages 51.9 (SD 11.96) and 48.1 (SD 13.86) years, respectively) (table 1). Most of the patients were in the most deprived quintile $(43.3 \%)$ of the SIMD with only $12.2 \%$ in the least deprived quintile. The mean initial weight at first attendance in phase 1 was $118.1 \mathrm{~kg}$, range $52.6-244.8 \mathrm{~kg}$. BMI was also high; the mean BMI at first attendance in phase 1 was 43.26 (43.34 in men and 43.23 in women). Nearly two-thirds $(63.1 \%)$ of patients had BMI of $40 \mathrm{~kg} / \mathrm{m}^{2}$ or greater (class III obesity).

The cumulative weight loss at the end of each phase is outlined in table 2. Almost three-quarters (72\%) of patients who started GCWMS attended at least four sessions, and of these 'completers', 36\% had lost $5 \mathrm{~kg}$ or more by the end of phase 1 . Twenty-six per cent of patients lost $5 \mathrm{~kg}$ or more when last weighed in phase 1 (LOCF) and this was similar when calculated on a BOCF basis. By the end of phase 2, 30\% of patients who started GCWMS had lost $5 \mathrm{~kg}$ or more when they were last weighed (LOCF). One-third of patients $(639 / 1838)$ who started GCWMS were deemed to have completed phase 2, and among them, $55 \%$ had lost $5 \mathrm{~kg}$ or more. The relatively low completion rate to the end of phase 2 (35\%) explains the large difference between BOCF and LOCF results. Relatively few patients attended up to the end of phase 2 and the BOCF assumes that weights did not change from baseline among the majority who did not provide a final weight. However, by using the last available weight, the LOCF indicates that $11 \%$ of patients who did not have a weight recorded by the end of phase 2 were known to have lost at least $5 \mathrm{~kg}$ when last seen. By the end of phase 3, $28 \%$ of patients who started GCWMS had lost $5 \mathrm{~kg}$ or more when they were 
Table 1 Baseline characteristics of 1838 patients who started phase 1 of Glasgow and Clyde Weight Management Service between October 2008 and September 2009

\begin{tabular}{|c|c|c|}
\hline & $\mathbf{N}$ & Per cent \\
\hline All & 1838 & 100 \\
\hline \multicolumn{3}{|l|}{ Gender } \\
\hline Male & 498 & 27.1 \\
\hline Female & 1340 & 72.9 \\
\hline \multicolumn{3}{|l|}{ Age (years) } \\
\hline$\leq 29$ & 192 & 10.5 \\
\hline 30-39 & 268 & 14.6 \\
\hline $40-49$ & 481 & 26.2 \\
\hline $50-59$ & 476 & 25.9 \\
\hline $60-69$ & 320 & 17.4 \\
\hline$\geq 70$ & 101 & 5.5 \\
\hline \multicolumn{3}{|l|}{ SIMD } \\
\hline Most deprived & 796 & 43.3 \\
\hline 2 & 342 & 18.6 \\
\hline 3 & 245 & 13.3 \\
\hline 4 & 224 & 12.2 \\
\hline Least deprived & 225 & 12.2 \\
\hline Not known & 6 & 0.3 \\
\hline \multicolumn{3}{|l|}{ Initial weight (kg) } \\
\hline $50-74$ & 12 & 0.7 \\
\hline $75-99$ & 395 & 21.5 \\
\hline $100-124$ & 813 & 44.2 \\
\hline $125-149$ & 464 & 25.2 \\
\hline$\geq 150$ & 154 & 8.4 \\
\hline \multicolumn{3}{|l|}{ Initial BMI $\left(\mathrm{kg} / \mathrm{m}^{2}\right)$} \\
\hline $30-34$ & 131 & 7.1 \\
\hline 35-39 & 546 & 29.7 \\
\hline $40-49$ & 872 & 47.4 \\
\hline$\geq 50$ & 289 & 15.7 \\
\hline
\end{tabular}

last weighed. In total, $11 \%$ of patients who started GCWMS complete phase 3 (208/1838), and among them, $58 \%$ had lost $5 \mathrm{~kg}$ or more. Table 2 also presents weight losses of $\geq 5 \%$. For over three-quarters of patients, a $5 \%$ weight loss meant loss of $>5 \mathrm{~kg}$ in weight; this resulted in fewer patients achieving the proportionate loss than the absolute loss.

Of the 1358 patients who did not lose at least $5 \mathrm{~kg}$ in phase 1, 461 (33.9\% using LOCF) entered phase 2. Their mean weight change in phase 2 was -0.65 (95\% CI -0.9 to $-0.4) \mathrm{kg}$. Of the complement of 480 patients who lost at least $5 \mathrm{~kg}$ in phase $1,339(70.6 \%)$ progressed into phase 2 . Their mean weight change in phase 2 was $-0.75(-1.1$ to -0.4$) \mathrm{kg}$.

As phase 2 represents the second and last of the weight-loss phases of GCWMS programme, we report determinants of weight loss by age, sex, socioeconomic circumstances, initial weight and initial BMI by the end of this phase in table 3 using the LOCF method. Men were generally more successful at losing the $5 \mathrm{~kg}$ target weight (mean losses in men and women were 4.16 and $3.4 \mathrm{~kg}$, respectively). Both men and women in all age groups from 30 to 70 years had similar success rates of about $30 \%$. However, patients aged 29 or under had different outcomes. Young men had greater success and young women had less success (52\% men vs $22 \%$ women under 30 years achieved $5 \mathrm{~kg}$ weight loss) although numbers of young men were small $(\mathrm{N}=25)$. Deprivation did not appear to affect the proportion losing their target weight. There was no clear trend between initial weight or BMI and successful weight loss, although patients who were heaviest had the greatest proportion of losing $5 \mathrm{~kg}$ or more $(41 \%$ of men and $48 \%$ of women).

In order to allow comparison of the results of GCWMS with other services that describe weight loss at

Table 2 Cumulative weight loss at end of each phase from first clinic visit in phase 1

\begin{tabular}{|c|c|c|c|c|c|}
\hline & $\mathbf{N}$ & Per cent & Mean change and $95 \% \mathrm{Cl}(\mathrm{kg})$ & Lost $\geq 5 \mathrm{~kg}$ & Lost $\geq 5 \%$ \\
\hline \multicolumn{6}{|l|}{ Phase 1} \\
\hline Completers & 1322 & 71.9 & $-4.02(-4.3$ to -3.8$)$ & $471(36 \%)$ & $377(29 \%)$ \\
\hline \multicolumn{6}{|l|}{ All cases } \\
\hline BOCF & 1838 & & $-2.89(-3.1$ to -2.7$)$ & $471(26 \%)$ & $377(21 \%)$ \\
\hline LOCF & 1838 & & $-3.06(-3.3$ to -2.9$)$ & $480(26 \%)$ & $381(21 \%)$ \\
\hline \multicolumn{6}{|l|}{ Phase 1+2 } \\
\hline Completers & 639 & 34.8 & $-6.38(-6.9$ to -5.8$)$ & $349(55 \%)$ & $313(49 \%)$ \\
\hline \multicolumn{6}{|l|}{ All cases } \\
\hline BOCF & 1838 & & $-2.22(-2.5$ to -2.0$)$ & $349(19 \%)$ & $313(17 \%)$ \\
\hline LOCF & 1838 & & $-3.6(-3.9$ to -3.4$)$ & $550(30 \%)$ & $468(25 \%)$ \\
\hline \multicolumn{6}{|c|}{ Phases $1+2+3^{\star}$} \\
\hline Completers & 208 & 11.3 & $-8.48(-9.7$ to -7.2$)$ & $121(58 \%)$ & $117(56 \%)$ \\
\hline \multicolumn{6}{|l|}{ All cases } \\
\hline BOCF & 1838 & & $-0.96(-1.1$ to -0.8$)$ & $121(7 \%)$ & $117(6 \%)$ \\
\hline LOCF & 1838 & & $-3.56(-3.8$ to -3.3$)$ & $509(28 \%)$ & $434(24 \%)$ \\
\hline
\end{tabular}

Completers attended $\geq 4$ sessions in phase $1, \geq 2$ sessions in phase 2 and $\geq 6$ sessions in phase 3 .

Duration of phases: phase 1,16 weeks; phase 2, 3 months (may be repeated); phase 3,12 months.

*Phase 3 completers must have completed phase 1 , and phase 2 if they entered it.

BOCF, baseline observation carried forward; LOCF, last observation carried forward. 
Table 3 Subgroup analyses of weight loss at end of phase 2, using LOCF method

\begin{tabular}{|c|c|c|c|c|c|c|c|c|}
\hline & \multicolumn{4}{|c|}{ Male } & \multicolumn{4}{|c|}{ Female } \\
\hline & $\mathbf{N}$ & $\begin{array}{l}\text { Mean weight } \\
\text { change and } \\
95 \% \mathrm{Cl}(\mathrm{kg})\end{array}$ & $\begin{array}{l}\text { Percentage } \\
\text { lost } \geq 5 \mathrm{~kg}\end{array}$ & $\begin{array}{l}\text { Percentage } \\
\text { lost } \geq 5 \%\end{array}$ & $\mathbf{N}$ & $\begin{array}{l}\text { Mean weight } \\
\text { change and } \\
95 \% \mathrm{Cl}(\mathrm{kg})\end{array}$ & $\begin{array}{l}\text { Percentage } \\
\text { lost } \geq 5 \mathrm{~kg}\end{array}$ & $\begin{array}{l}\text { Percentage } \\
\text { lost } \geq 5 \%\end{array}$ \\
\hline All & 498 & $-4.16(-4.7$ to -3.6$)$ & 33 & 24 & 1340 & $-3.4(-3.7$ to -3.1$)$ & 29 & 26 \\
\hline$\leq 29$ years & 25 & $-5.17(-7.8$ to -2.6$)$ & 52 & 24 & 167 & $-2.16(-2.9$ to -1.4$)$ & 22 & 20 \\
\hline 30-39 years & 58 & $-3.19(-4.4$ to -2.0$)$ & 31 & 16 & 210 & $-3.81(-4.6$ to -3.0$)$ & 32 & 27 \\
\hline 40-49 years & 122 & $-4.75(-6.1$ to -3.4$)$ & 32 & 26 & 359 & $-3.45(-4.0$ to -2.9$)$ & 30 & 25 \\
\hline 50-59 years & 152 & $-4.16(-5.3$ to -3.0$)$ & 34 & 26 & 324 & $-3.84(-4.4$ to -3.3$)$ & 31 & 28 \\
\hline $60-69$ years & 119 & $-3.69(-4.6$ to -2.8$)$ & 30 & 24 & 201 & $-3.09(-3.6$ to -2.5$)$ & 25 & 23 \\
\hline$\geq 70$ years & 22 & $-4.93(-7.9$ to -2.0$)$ & 27 & 23 & 79 & $-3.66(-4.5$ to -2.8$)$ & 30 & 38 \\
\hline $\begin{array}{l}1 \text { (most } \\
\text { deprived) }\end{array}$ & 204 & $-4.02(-4.9$ to -3.1$)$ & 32 & 22 & 592 & $-3.23(-3.6$ to -2.8$)$ & 28 & 24 \\
\hline 2 & 79 & $-3.55(-4.7$ to -2.4$)$ & 32 & 22 & 263 & $-3.61(-4.2$ to -3.0$)$ & 32 & 30 \\
\hline 3 & 65 & $-3.83(-5.3$ to -2.4$)$ & 32 & 25 & 180 & $-3.54(-4.2$ to -2.9$)$ & 33 & 29 \\
\hline 4 & 63 & $-5.24(-7.1$ to -3.3$)$ & 37 & 29 & 161 & $-2.97(-3.8$ to -2.1$)$ & 22 & 21 \\
\hline $\begin{array}{l}5 \text { (least } \\
\text { deprived) }\end{array}$ & 83 & $-4.61(-6.1$ to -3.1$)$ & 34 & 28 & 142 & $-4.01(-4.9$ to -3.2$)$ & 30 & 28 \\
\hline \multicolumn{9}{|c|}{ Initial weight (kg) } \\
\hline $75-99$ & 24 & $-4.84(-6.4$ to -3.2$)$ & 38 & 46 & 383 & $-2.69(-3.1$ to -2.3$)$ & 21 & 25 \\
\hline $100-124$ & 188 & $-3.21(-3.9$ to -2.6$)$ & 27 & 21 & 625 & $-3.34(-3.7$ to -3.0$)$ & 28 & 25 \\
\hline $125-149$ & 192 & $-4.39(-5.4$ to -3.4$)$ & 34 & 24 & 272 & $-4.17(-4.9$ to -3.4$)$ & 36 & 26 \\
\hline$\geq 150$ & 94 & $-5.44(-7.2$ to -3.7$)$ & 41 & 26 & 60 & $-5.04(-7.2$ to -2.9$)$ & 48 & 38 \\
\hline \multicolumn{9}{|c|}{ Initial BMI $\left(\mathrm{kg} / \mathrm{m}^{2}\right)$} \\
\hline $30-34$ & 40 & $-3.55(-4.8$ to -2.3$)$ & 30 & 32 & 91 & $-2.75(-3.6$ to -1.9$)$ & 21 & 25 \\
\hline $35-39$ & 136 & $-3.0(-3.8$ to -2.2$)$ & 24 & 18 & 410 & $-3.13(-3.5$ to -2.7$)$ & 26 & 27 \\
\hline $40-49$ & 242 & $-4.32(-5.1$ to -3.5$)$ & 35 & 25 & 630 & $-3.49(-3.9$ to -3.1$)$ & 29 & 25 \\
\hline$\geq 50$ & 80 & $-5.97(-8.1$ to -3.9$)$ & 43 & 29 & 209 & $-3.93(-4.8$ to -3.1$)$ & 38 & 28 \\
\hline
\end{tabular}

BMI, body mass index; LOCF, last observation carried forward. 
Table 4 Cumulative weight changes at specified time from first clinic visit for 1838 patients, October 2008 to September 2009

\begin{tabular}{|c|c|c|c|c|c|}
\hline & $\mathbf{N}$ & Per cent & Mean change and $95 \% \mathrm{Cl}(\mathbf{k g})$ & Lost $\geq 5 \mathrm{~kg}$ & Lost $\geq 5 \%$ \\
\hline \multicolumn{6}{|l|}{3 months } \\
\hline Complete cases & 1167 & 63.5 & $-3.7(-3.9$ to -3.5$)$ & $369(32 \%)$ & $289(25 \%)$ \\
\hline BOCF & 1838 & & $-2.4(-2.5$ to -2.2$)$ & $369(20 \%)$ & $289(16 \%)$ \\
\hline LOCF & 1838 & & $-2.7(-2.9$ to -2.5$)$ & $399(22 \%)$ & $308(17 \%)$ \\
\hline \multicolumn{6}{|l|}{6 months } \\
\hline Complete cases & 701 & 38.1 & $-5.8(-6.3$ to -5.4$)$ & $347(50 \%)$ & $310(44 \%)$ \\
\hline BOCF & 1838 & & $-2.2(-2.4$ to -2.0$)$ & $347(19 \%)$ & $310(17 \%)$ \\
\hline LOCF & 1838 & & $-3.4(-3.6$ to -3.2$)$ & $515(28 \%)$ & $433(24 \%)$ \\
\hline \multicolumn{6}{|l|}{12 months } \\
\hline Complete cases & 399 & 21.7 & $-7.2(-8.1$ to -6.3$)$ & $214(54 \%)$ & $203(51 \%)$ \\
\hline BOCF & 1838 & & $-1.6(-1.8$ to -1.3$)$ & $214(12 \%)$ & $203(11 \%)$ \\
\hline LOCF & 1838 & & $-3.6(-3.9$ to -3.3$)$ & $612(28 \%)$ & 447 (24\%) \\
\hline
\end{tabular}

fixed time points, we calculated weight changes at 3,6 and 12 months (table 4)-although these are not recognised as end points by GCWMS. These roughly correspond to the ends of phases 1 and 2 while phase 3 corresponds to a time point of between 18 and 24 months. GCWMS does not aim to achieve $5 \mathrm{~kg}$ weight losses as early as 3 months, so the 6 and 12 months results are most meaningful. At both 6 and 12 months after starting at GCWMS, $28 \%$ of patients (LOCF) had lost $5 \mathrm{~kg}$ or more of their initial weight. Of patients with a weight measured at around 6 months, $50 \%$ had lost $5 \mathrm{~kg}$ or more and of those who had actual weights recorded around 12 months, $54 \%$ lost $5 \mathrm{~kg}$ or more. However, because only $21.7 \%$ had their weights recorded at 12 months, it can only be said for certain that $12 \%$ of all patients who began the programme had definitely lost $5 \mathrm{~kg}$ or more at this time point.

\section{DISCUSSION}

NHS GCWMS achieved a $5 \mathrm{~kg}$ weight loss in $28 \%$ of participants at 12 months when the LOCF analysis is used. This equates to $24 \%$ of participants losing $5 \%$ of their body weight, because the mean weight was greater than $100 \mathrm{~kg}$ at baseline. When complete cases are considered, $54 \%$ of participants achieved at least $5 \mathrm{~kg}$ weight loss at 12 months. Overall, men achieved greater weight loss than did women. Those with very high initial weight (>150 kg) also did well with $48 \%$ of women and $41 \%$ of men losing $5 \mathrm{~kg}$ or more (38\% and $26 \%$, respectively losing $5 \%$ ).

Owing to methodological differences, comparisons with other published data are difficult. Data from commercial weight management programmes show WeightWatchers to be a successful intervention with between $31 \%^{11}$ and $51 \%^{7}$ of participants losing $5 \mathrm{~kg}$ or $5 \%$ of their body weight. ${ }^{8}$ However, these data were from randomised research studies with mean BMIs under $38 \mathrm{~kg} / \mathrm{m}^{2}$ compared with the GCWMS mean of $43 \mathrm{~kg} / \mathrm{m}^{2}$. There were also differences in data collection, with the Lighten Up study using patient selfreport for final weight, a method known to result in under-reporting of weight. ${ }^{12}$ It is not known why some patients drop out of weight management programmes, although within GCWMS, patients are given a target weight loss of $5 \mathrm{~kg}$ and then offered the option of longer term support of up to 2 years. Participants can choose to leave earlier than this with possible reasons ranging from lack of success and weight regain to weight loss success and the feeling they can 'go it alone' and no longer need the service; this makes the issue of missing data very difficult and explains why we and other studies get large differences in results when using baseline or LOCF. Our definition of course completion was lower than some others have used and given that attendance is directly related to weight loss, it is likely that if we used a higher threshold for completion, weight losses would have been greater in this group. It is difficult to compare the final opt-in proportion, $62 \%$, with that of other studies in which very different recruitment methods are used, such as widespread postal invitations, rather than the individual GP referrals from GCWMS. Retention of patients in GCWMS appears to be lower than that in some other studies but the aim of the service is not to retain all patients to the end of phase 3 but rather to be flexible in allowing them to leave if they have succeeded in losing their target weight.

Currently, the GCWMS is based around a target of achieving a $5 \mathrm{~kg}$ weight loss. However, given the higher BMI of participants in this specialist service, $5 \mathrm{~kg}$ is only $4.2 \%$ of the mean body weight, as opposed to the $5 \mathrm{~kg}$ and $5 \%$ being interchangeable outcomes in a population whose mean weight is closer to $100 \mathrm{~kg}$. Given the higher initial BMI and range of comorbidities in the GCWMS population, it could be argued that higher weight loss targets should be set. Bariatric surgery has shown health benefits for larger weight losses than those achieved by conventional weight management programmes ${ }^{17}$ and there are new non-surgical interventions such as drug treatments, ${ }^{18} 19$ which promote weight losses greater than $5 \mathrm{~kg}$ as well as the recent rival of the popularity of low-energy liquid diets, which have the potential for larger weight loss and also to modify obesity-related comorbidities. $^{20} 21$ 
The major strength of our results are that they come from a very large NHS service specifically targeting severe and complex obesity, an area of concern due to the healthcare costs of such patients. ${ }^{22}$ We have provided a comprehensive description of the outcomes using baseline and LOCF as well as linking outcomes to the programme structure and time-based observations. While there are many NHS weight management programmes across the UK, the majority are poorly evaluated or not at all, making their effectiveness difficult to ascertain. This results in a lack of evidence for the commissioning and decommissioning of these services and does not help in building arguments for investment in such services at a time of financial constraint. There is an urgent need to define consistent analytical methods, including how missing data should be treated, and acceptable ranges when describing time points.

The major weakness in our current work is the lack of ancillary information such as baseline characteristics and changes in clinical risk factors (eg, blood pressure, lipids and glycaemic control) or change in medications. This is due to the data being from a real-life NHS service rather than a study population, but clearly data collection could be improved for future evaluations. Where BMI-specific weight changes have been reported elsewhere in the UK, there is some evidence that patients with greater baseline weights were more likely to lose weight ${ }^{7}$ although Ahern reported a weight gain in patients with class III obesity (BMI $\left.\geq 40 \mathrm{~kg} / \mathrm{m}^{2}\right)$. Our definition of course completion was lower than some others have used and given that attendance is directly related to weight loss, it is likely that if we used a higher threshold for completion, weight losses would have been greater in this group.

In conclusion, this is the first publication of 12-month results of a large NHS weight management programme specifically targeted at patients with severe obesity. We have shown modest results in achieving some success with a $5 \mathrm{~kg}$ or greater weight loss in $28 \%$ of our patients at 1 year but it is hard to compare these results with that from others programmes. There is an urgent need for standardised data collection from weight management programmes. Consideration needs to be given as to the treatment target in severely obese patients and how best to achieve this within NHS services.

Contributors MG carried out extraction, cleaning and interpretation of data. GA carried out all statistical analyses. JL, GA and DSM drafted the manuscript; $M G$ and LF commented on a late draft. All authors designed the study and approved the final draft of the manuscript.

Funding This research received no specific grant from any funding agency in the public, commercial or not-for-profit sectors.

\section{Competing interests None.}

Provenance and peer review Not commissioned; externally peer reviewed.

Data sharing statement The Glasgow and Clyde Weight Management Service database includes additional variables that have not been extracted or analysed as part of this work. Applications for a list of variables should be sent in the first instance to the corresponding author.

Open Access This is an Open Access article distributed in accordance with the Creative Commons Attribution Non Commercial (CC BY-NC 3.0) license, which permits others to distribute, remix, adapt, build upon this work noncommercially, and license their derivative works on different terms, provided the original work is properly cited and the use is non-commercial. See: http:// creativecommons.org/licenses/by-nc/3.0/

\section{REFERENCES}

1. Ding EL, Malik VS. Convergence of obesity and high glycemic diet on compounding diabetes and cardiovascular risks in modernizing China: an emerging public health dilemma. Global Health 2008;4:4.

2. Berghofer A, Pischon T, Reinhold T, et al. Obesity prevalence from a European perspective: a systematic review. BMC Public Health 2008;8:200.

3. Wang YC, Colditz GA, Kuntz KM. Forecasting the obesity epidemic in the aging U.S. population. Obesity (Silver Spring) 2007;15:2855-65.

4. Kopelman P. Health risks associated with overweight and obesity. Obes Rev 2007:8(Suppl 1):13-17.

5. Scottish Intercollegiate Guidelines Network (SIGN). Management of obesity. Guideline 115. Edinburgh: SIGN, 2010.

6. National Institute for Health and Clinical Excellence. CG43. Obesity guidance on the prevention, identification, assessment and management of overweight and obesity in adults and children. London: NICE, 2006.

7. Dixon KJ, Shcherba S, Kipping RR. Weight loss from three commercial providers of NHS primary care slimming on referral in North Somerset: service evaluation. J Public Health (Oxf) 2012;34:555-61.

8. Ahern AL, Olson AD, Aston LM, et al. Weight Watchers on prescription: an observational study of weight change among adults referred to Weight Watchers by the NHS. BMC Public Health 2011;11:434.

9. Stubbs RJ, Pallister C, Whybrow S, et al. Weight outcomes audit for 34,271 adults referred to a primary care/commercial weight management partnership scheme. Obes Facts 2011; 4:113-20.

10. Nanchahal K, Power T, Holdsworth $\mathrm{E}$, et al. A pragmatic randomised controlled trial in primary care of the Camden Weight Loss (CAMWEL) programme. BMJ Open 2012;2:e000793.

11. Jolly $\mathrm{K}$, Lewis $\mathrm{A}$, Beach $\mathrm{J}$, et al. Comparison of range of commercial or primary care led weight reduction programmes with minimal intervention control for weight loss in obesity: Lighten Up randomised controlled trial. BMJ 2011;343:d6500.

12. Connor GS, Tremblay M, Moher D, et al. A comparison of direct vs. self-report measures for assessing height, weight and body mass index: a systematic review. Obes Rev 2007;8:307-26.

13. Counterweight Project Team. Evaluation of the counterweight programme for obesity management in primary care: a starting point for continuous improvement. Br J Gen Pract 2008; 58:548-54.

14. Jebb SA, Ahern AL, Olson AD, et al. Primary care referral to a commercial provider for weight loss treatment versus standard care: a randomised controlled trial. Lancet 2011;378:1485-92.

15. Morrison DS, Boyle S, Morrison C, et al. Evaluation of the first phase of a specialist weight management programme in the UK National Health Service: prospective cohort study. Public Health Nutr 2012;15:28-38.

16. Scottish Index of Multiple Deprivation. http://www.scotland.gov.uk/ Topics/Statistics/SIMD (accessed 15 Nov 2013).

17. Sjostrom L, Narbro K, Sjostrom CD, et al. Effects of bariatric surgery on mortality in Swedish obese subjects. N Engl J Med 2007;357:741-52.

18. Smith SR, Weissman NJ, Anderson CM, et al. Multicenter, placebocontrolled trial of lorcaserin for weight management. N Engl J Med 2010;363:245-56.

19. Astrup A, Rossner S, Van Gaal L, et al. Effects of liraglutide in the treatment of obesity: a randomised, double-blind, placebo-controlled study. Lancet 2009;374:1606-16.

20. Johansson K, Hemmingsson E, Harlid R, et al. Longer term effects of very low energy diet on obstructive sleep apnoea in cohort derived from randomised controlled trial: prospective observational follow-up study. BMJ 2011;342:d3017.

21. Lim EL, Hollingsworth KG, Aribisala BS, et al. Reversal of type 2 diabetes: normalisation of beta cell function in association with decreased pancreas and liver triacylglycerol. Diabetologia 2011;54:2506-14.

22. Counterweight Project Team. Influence of body mass index on prescribing costs and potential cost savings of a weight management programme in primary care. $J$ Health Serv Res Policy 2008;13:158-66. 